\title{
EVALUASI TATA KELOLA DAN KINERJA KELEMBAGAAN KOMISI IRIGASI (KOMIR) KABUPATEN PANDEGLANG
}

\author{
EVALUATION OF GOVERNANCE AND INSTITUTIONAL PERFORMANCE OF THE \\ IRIGATION COMMISSION (KOMIR), PANDEGLANG REGENCY
}

\author{
NIKEN MARETA RINDASARI, JULELAH, NENENG MASITOH \\ Fakultas Ekonomi dan Bisnis, Universitas Bina Bangsa \\ *Email : nikenja999@gmail.com
}

\begin{abstract}
ABSTRAK
Penelitian ini bertujuan untuk (i) mengidentifikasi berbagai pencapaian dan realisasi program kerja komisi irigasi, (ii) menilai kinerja kelembagaan komisi irigasi dan (ii) merekomendasikan perbaikan kelembagaan komisi irigasi di Kabupaten Pandeglang. Metode pengumpulan data yang digunakan dalam penelitian ini berbagai strategi, diantaranya adalah gabungan antara metode dokumentasi dan survei yang dilengkapi dengan metode observasi. Untuk penilaian kinerja komisi irigasi dengan metode penilaian cepat secara partisipatif terhadap 3 variabel meliputi pembentukan, sekretariat dan pendanaan yang di uraikan kedalam 10 variabel dengan 25 indikator penilaian kinerja komisi irigasi. Komisi irigasi telah melakukan 3 (tiga) sidang komisi irigasi dengan melakukan pengesahan tata tertib sidang dan menyusun Penyusunan dan Penetapan RTTG dan RTTD masa Tanam 2019 - 2020. Hasil penilaian kinerja komisi irigasi mendapatkan nilai skor 70 dengan kategori berkinerja cukup. Penilaian tersebut menjelaskan dalam pengelolaan kelembagaan komisi irigasi terdapat beberapa kendala yang perlu untuk di tingkatkan meliputi ketersediaan tenaga ahli dan narasumber dalam berbagai pelaksanaan kegiatan komisi irigasi, masih rendahnya dukungan pendanaan untuk kegiatan operasional komisi irigasi, dan sekretariat komisi irigasi yang masih bersifat sementara (sewa).
\end{abstract}

Kata Kunci: Dukungan Pemerintah, Rencana Kerja, Kinerja Komisi Irigasi

\section{ABSTRACT}

This study aims to (i) identify the various achievements and realization of the work program of the irrigation commission, (ii) assess the institutional performance of the irrigation commission and (ii) recommend the institutional improvement of the irrigation commission in Pandeglang Regency. Data collection methods used in this study various strategies, including a combination of documentation and survey methods that are equipped with observation methods. For the irrigation commission performance appraisal with a participatory rapid appraisal method of 3 variables including the formation, secretariat and funding which are broken down into 10 variables with 25 indicators of irrigation commission performance appraisal. The irrigation commission has conducted 3 (three) sessions of the irrigation commission by ratifying the trial order and compiling the Arrangement and Determination of the RTTG and RTTD for Planting Period 2019 - 2020. The irrigation commission performance appraisal results obtained a score of 70 with the category of sufficient performance. The assessment explained that in the institutional management of the irrigation commission, there were several obstacles that needed to be improved, including the availability of experts and resource persons in various irrigation commission activities, the low funding support for the irrigation commission operational activities, and the irrigation commission secretariat which was still temporary (rent) .

Keywords: Government Support, Work Plan, Irrigation Commission Performance

\section{PENDAHULUAN}

Pengelolaan sistem irigasi yang baik menjadi kebutuhan yang utama bagi sektor pertanian di Kabupaten Pandeglang, menginggat sektor ini memberikan konstribusi melebih $35 \%$ pada Produk 
Domestik Regional Bruto (BPS Kabupaten Pandeglang, 2019) dan konstribusi strategis dalam penyediaan lapangan kerja bagi masyarakat pedesaan di Kabupaten Pandeglang. Disamping itu, ketersediaan sistem irigasi yang baik dapat mendorong peningkatan produktivitas hasil pertanian untuk menjaga ketahanan pangan di daerah (Tri Bastuti Purwantini \& Rita Nur Suhaeti, 2017). Keberadaan sistem irigasi yang baik mampu mendorong peningkatan produksi pertanian yang pada akhirnya akan mendorong peningkatan kesejahteraan petani. Peningkatan kesejahteraan petani yang massif secara langsung menjaga proses produksi yang berkelanjutan, hal inilah bagian utama dalam kebijakan ketahanan pangan secara nasional (Sekretariat Negara Republik Indonesia, 2006).

Dalam pengelolaan irigasi di suatu wilayah sangatlah banyak pihak-pihak yang berkepentingan baik pemerintah, pengelola jarigan irigasi dan petani pemanfaat jarigan irigasi. Menginggat banyaknya pihak yang terlibat dalam pemanfaatan jaringan irigasi, maka seyogyanya irigasi menjadi satu kesatuan sistem yang dikelola secara partisipatif untuk menjaga keberlangsungan jaringan irigasi tersebut (Kurniasih Budi, 2018). Pengelolaan irigasi yang melibatkan banyak unsur, diantaranya Pemerintah
Daerah, Petani Pemakai Air (P3A/GP3A/IP3A), kelompok tani (Poktan/Gapoktan), dan pengguna jaringan irigasi lainnya haruslah dikoordinasikan kegiatannya dengan baik. Untuk mendorong terwujudnya koordinasi kegiatan, maka dibutuhkan kelembagaan Komisi Irigasi. Secara prinsip Komisi Irigasi sebagai lembaga koordinasi dan komunikasi dalam implementasi kebijakan pengembangan dan pengelolaan sistem irigasi partisipatif.

Komisi Irigasi sebagai kelembagaan non struktural memiliki keberfungsian sebagai forum koordinasi antara pemerintah dan masyarakat petani pemanfaatan air untuk irigasi dan lainnya(Djito, 2016). Keberadaan komisi irigasi memiliki nilai yang strategis dalam perencanaan dan pengelolaan daerah irigasi yang lebih efektif dan efisien, menginggat kelembagaan komisi irigasi memberikan rekomendasi perencanaan irigasi yang menentukan rencana tanam bagi petani, terutama pada komoditas padi (Eko Aristanto, 2020b). Disamping itu, keberadaan komisi irigasi juga merekomedasi berbagai pemikiran yang mendorong perbaikan kebijakan-kebijakan di bidang irigasi yang tentunya akan berdampak langsung pada pertanian di daerah Kabupaten Pandeglang. Adapun 
kelembagaan Komisi Irigasi di Kabupaten Pandeglang ditetapkan oleh Bupati Pandeglang dalam Surat Keputusan Bupati Pandeglang Nomor 050/Kep.221-Huk/2019 tentang Pembentukan Komisi Irigasi Kabupaten Pandeglang (Badan Perencanaan Pembangunan Daerah Kabupaten Pandeglang, 2019a).

$$
\text { Dalam pelaksanaan Program }
$$

Integrated Participatory Development and Managemet of Irrigation Program (IPDMIP) mendorong perkembangan dan keberfungsian kelembagaan Komisi Irigasi bagi peningkatan pembangunan bidang pertanian (Kementerian Pekerjaan Umum dan Perumahan Rakyat, 2017). Peningkatan peran Komisi Irigasi merupakan bagian Disbursement Link Indicator ke 3 dari Program Integrated Participatory Development and Managemet of Irrigation Program (IPDMIP) yang harus dapai dicapai dalam program (Eko Aristanto, 2020a). Merujuk latar belakang di atas, menjelaskan keberadaan Komisi Irigasi mempunyai nilai strategis dalam menentukan arah kebijakan dan programprogram bidang irigasi yang berdampak langsung terhadap sektor pertanian. Penelitian ini bertujuan untuk (i) mengidentifikasi berbagai pencapaian dan realisasi program kerja komisi irigasi di Kabupaten Pandeglang, (ii) menilai kinerja kelembagaan komisi irigasi di Kabupaten Pandeglang, dan (ii) merekomendasikan perbaikan kelembagaan komisi irigasi di Kabupaten Pandeglang.

\section{METODE PENELITIAN}

Pelaksanaan penelitian ini mengunakan penelitian deskripsi kualitatif dan kuantitatif. Adapun variabel kinerja kuantitatif secara umum lebih objektif berdasarkan angka-angka. Sedangkan variabel kinerja kualitatif diperlukan untuk menilai tata kelola dan kinerja organisasi yang tidak cukup hanya berdasarkan angka (Eko Aristanto, 2020c). Metode pengumpulan mengunakan metode dokumentasi, metode observasi dan metode focus group discussion (FGD). Penilaian kinerja komisi irigasi dengan penilaian cepat secara partisipatif (participatory rapid assessment). Indikator penilaian kinerja komisi irigasi, secara operasional penilaian kinerja Komisi Irigasi berdasarkan Panduan Pemantauan dan Penilaian Kinerja Komisi Irigasi (KOMIR) IPDMIP (Kementerian Dalam Negeri, 2018) melalui 3 variabel utama, yaitu : 
Tabel 1. Indikator Kinerja dan Proporsi Skor

\begin{tabular}{|c|c|c|c|c|}
\hline \multirow{3}{*}{$\begin{array}{c}\text { No } \\
1\end{array}$} & Variabel & Parameter & \multicolumn{2}{|c|}{ Bobot Skoring } \\
\hline & & & & \\
\hline & Pembentuk- an & $\begin{array}{l}\text { 1. Legalisasi Penentuk- an } \\
\text { Komir dan Sekretariat. }\end{array}$ & 8 & 30 \\
\hline & & 2. Struktur Organisasi. & 6 & \\
\hline & & 3. Keanggotaan. & 16 & \\
\hline 2 & Sekretariat & 4. Tenaga Pelaksana. & 8 & 40 \\
\hline & & 5. Program Kerja. & 8 & \\
\hline & & 6. Pelaksanaan Tugas. & 6 & \\
\hline & & 7. Hasil Kerja Sekretariat & 12 & \\
\hline & & 8. Fasilitas Pendukung & 6 & \\
\hline 3 & Pendanaan & 9. Operasio- nal & 20 & 30 \\
\hline & & 10. Pertang- gung jawaban & 10 & \\
\hline & 3 Variabel & 10 Parameter (25 Indikator) & 100 & 100 \\
\hline
\end{tabular}

Adapun tolak ukur penilaian yang dibagi dalam 3 (tiga) kelompok penilaian dengan skala 0 - 100 tingkat kinerja Komisi Irigasi sebagai berikut :

Tabel 2. Skor dan Kategori Hasil Penilaian Kinerja

\begin{tabular}{cll}
\hline No. & \multicolumn{1}{c}{ Skor } & \multicolumn{1}{c}{ Kategori } \\
\hline 1 & $\mathrm{~N}<50$ & Kinerja Kurang Baik \\
2 & $51<\mathrm{N}<75$ & Kinerja Cukup \\
3 & $76<\mathrm{N}<100$ & Kinerja Baik \\
\hline
\end{tabular}

\section{HASIL DAN PEMBAHASAN}

Keberadaan Komisi Irigasi

Kabupaten Pandeglang ditetapkan dalam

Keputusan Bupati Pandeglang Nomor 050/Kep.221-Huk/2019 tentang

Pembentukan Komisi Irigasi Kabupaten
Pandeglang. Dengan telah ditetapkannya kelembagaan komisi irigasi tersebut, maka pelaksanaan berbagai kegiatan dan rencana kerja dapat mulai di jalankan. Merujuk pada Keputusan Bupati Pandeglang di atas, maka kelembagaan Komisi Irigasi Kabupaten Pandeglang di isi oleh 2 (dua) unsur utama yakni unsur pemerintah dan unsur non pemerintah. Adapun struktur organisasi Komisi Irigasi Kabupaten Pandeglang berdasarkan Keputusan Bupati Pandeglang Nomor 050/Kep.221-Huk/2019 tentang Pembentukan Komisi Irigasi Kabupaten Pandeglang sebagai berikut : 


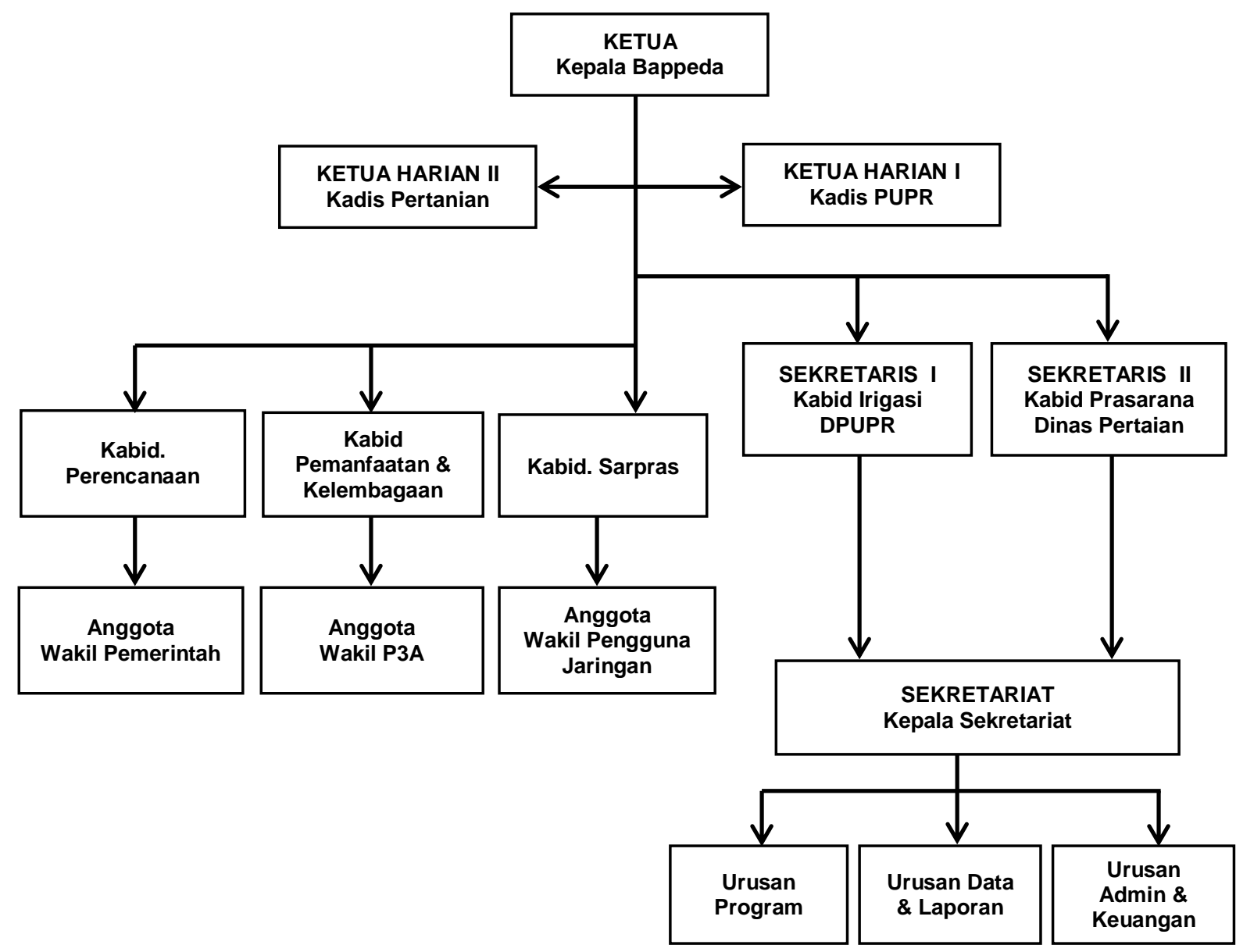

Gambar 1. Struktur Organisasi Komisi Irigasi Kabupaten Pandeglang Sumber : Bappeda Kabupaten Pandeglang

Dalam kontek administrasi kelembagaan komisi irigasi telah memiliki payung hukum dalam pelaksanaan kerjanya dengan diterbitkannnya Surat Keputusan Bupati Pandeglang Nomor 050/Kep.221Huk/2019 tentang Pembentukan Komisi Irigasi Kabupaten Pandeglang. Dalam kelembagaan tersebut telah mengakomodasi 2 (dua) unsur yakni keterwakilan unsur pemerintah dan keterwakilan unsur non pemerintah (Badan Perencanaan Pembangunan Daerah Kabupaten
Pandeglang, 2019b). Unsur keterwakilan pemerintah sebanyak 10 perwakilan organisasi perangkat daerah terdiri dari 1) Kepala Bapeda, 2) Kepala Dinas Pekerjaan Umum dan Penataan Ruang, 3) Kepala Dinas Pertanian, 4) Kepala Dinas Perikanan, 5) Kabid. SDA DPUPR, 6) Kabib. Prasarana dan Sarana Dinas Pertanian,7) Kabag. Hukum SEKDA, 8) Kabid. Fisik dan Prasarana Bappeda, 9) Kabid. Penyluhan Dinas Pertanian dan 10) Kasi Eksplotasi dan Pemeliharaan DPUR. 
Sedangkan keterwakilan unsur non Kontak Tani dan Nelayan, 10) Kelomok pemerintah sebanyak 12 perwakilan kelembagaan P3A, Kotak Tani dan Nelayan dan Kelompok Wanita Tani yang terdiri dari 1) P3A Sumber Tani, 2) P3A Mekarwangi III, 3) P3A Mandalasari, 4) P3A Sumber Makmur, 5) P3A Lembah Gunug Raya, 6) P3A Harapan Makmur, 7) Pembudidaya Ikan “Bina Praja 9", 11) Ketua Kelompok Wanita Sukaratu dan 12) Kelompok Wanita Tani Cilaja. Namun proporsi keterlibatan kelompok perempuan dalam kelembagaan komisi irigasi masih rendah di bawah $20 \%$ dari keanggotaan P3A Cipunga, 8) 3A Cihoe Makmur, 9

\section{Tabel 3. Pelaksanaan Sidang Komisi Irigasi Kabupaten Pandeglang}

\begin{tabular}{|c|c|c|c|}
\hline No. & Sidang & Pelaksanaan & Keterangan \\
\hline 1 & $\begin{array}{l}\text { Sidang } \\
\text { Komisi } \\
\text { Irigasi I }\end{array}$ & $\begin{array}{l}\text { Rabu, } \\
16 \text { Oktober } \\
2019\end{array}$ & $\begin{array}{l}\text { Resume Sidang Komisi Irigasi I sebagai berikut : } \\
\text { 1) Kelembagaan Komisi Irigasi terdapat ada } 6 \text { (enam) kegiatan } \\
\text { 2) Rumusan Kebijakan KOMIR terdapat } 11 \text { (sebelas) kegiatan } \\
\text { 3) Diputuskan RTTG dan RTTD untuk masa tanam 2019-2020 } \\
\text { 4) Sidang Komisi Irigasi ke } 2 \text { dilakukan pada Akhir Bulan } \\
\text { Oktober 2019 } \\
\text { 5) Sosialisasi SK Masa Tanam 2019-2020 dilakukan pada Awal } \\
\text { Bulan Nopember } 2019\end{array}$ \\
\hline 2 & $\begin{array}{l}\text { Sidang } \\
\text { Komisi } \\
\text { Irigasi II }\end{array}$ & $\begin{array}{l}\text { Senin, } \\
28 \text { Oktober } \\
2019\end{array}$ & $\begin{array}{l}\text { Resume Sidang Komisi Irigasi I sebagai berikut : } \\
\text { 1) Tim Sekretariat agar menyusun finalisasi draft - draft yang } \\
\text { telah disepakati bersama ; } \\
\text { 2) Penyusunan dan penetapan Tata Tertib Sidang Komir dan } \\
\text { Rencana } 5 \text { tahunan dan } 1 \text { Tahunan melalui SK. Ketua KOMIR; } \\
\text { 3) Penyusunan dan Penetapan RTTG dan RTTD masa Tanam } 2019 \\
\text { - } 2020 \text { melalui SK. Bupati Pandeglang. }\end{array}$ \\
\hline 3 & $\begin{array}{l}\text { Sidang } \\
\text { Komisi } \\
\text { Irigasi III }\end{array}$ & $\begin{array}{l}\text { Jumat, } 20 \\
\text { Desember } \\
2019\end{array}$ & $\begin{array}{l}\text { Resume Sidang Komisi Irigasi I sebagai berikut : } \\
\text { 1) Dalam rangka peningkatan kapasitas SDM lembaga pengelola } \\
\text { irigasi, dimana pada tiap pelaksanaan sidang agar } \\
\text { menghadirkan Tenaga Ahli yang dapat memberikan tambahan } \\
\text { wawasan terkait dengan pengelolaan irigasi; } \\
\text { 2) Peran, Tugas dan Fungsi Sekretariat sangat vital dalam } \\
\text { menopang kinerja Lembaga Sidang Komisi Irigasi. Tim } \\
\text { sekretariat yaang agar dapat dibentuk kembali mengingat } \\
\text { adanya pergantian pejabat beberapa waktu yang lalu; } \\
\text { 3) Terkait dengan kesetaraan gender menjadi isu dalam program } \\
\text { IPDMIP sehingga pada tiap tahapan pelaksanaan keterlibatan } \\
\text { perempuan diharuskan. } \\
\text { 4) TPM dapat dilibatkan dalam kegiatan pemberdayaan } \\
\text { P3A/GP3A } \\
\text { Keberadaan komisi irigasi kiranya dapat berperan lebih } \\
\text { strategis dalam setiap pengelolaan irigasi untuk membanguan } \\
\text { keandalan sistem pengelolaan irigasi dalam rangka } \\
\text { mewujudkan ketahanan pangan }\end{array}$ \\
\hline
\end{tabular}


Semenjak pengesahan komisi irigasi oleh Bupati Pandeglang di pertengahan tahun 2019 sampai dengan akhir tahun 2019. Komisi Irigasi Kabupaten Pandeglang telah melaksanakan 3 (tiga) kali Sidang Komisi Irigasi dengan beberapa hasil rekomendasi sidang komisi irigasi meliputi : 1) Pengesahan Tata Tertib Sidang Komisi Irigasi, 2) Penetapan RTTG dan RTTD masa Tanam 2019 - 2020 melalui SK. Bupati Pandeglang, 3) Rencana Kerja Tahunan dan 5 Tahunan Komisi Irigasi, 4) Pembahasan Peraturan Daerah Irigasi pasca pemberlakukan Undang-Undang Nomor 17 Tahun 2019 tentang Sumber Daya Air, 5) Penyediaan Tenaga Ahli yang membantu peningkatan kinerja komisi irigasi.

\section{Penilaian Kinerja Komisi Irigasi Kabupaten Pandeglang}

Penilaian kinerja komisi irigasi adalah upaya nyata untuk menilai bagaimana kelembagaan komisi irigasi merencanakan dan bekerja sesuai dengan tugas pokok dan fungsi komisi irigasi dengan memperhatian seluruh variabel dann paramater kinerja komisis irigasi Adapun hasil penilaian kinerja komisi irigasi dengan mengunakan indikator kinerja Komisi Irigasi berdasarkan Panduan Pemantauan dan Penilaian Kinerja Komisi Irigasi (KOMIR) IPDMIP (Kementerian Dalam Negeri, 2018) dengan hasil sebagai berikut :

Tabel 4. Hasil Penilaian Kinerja Komisi Irigasi Kabupaten Pandeglang.

\begin{tabular}{|c|c|c|c|c|c|}
\hline Variabel & & Parameter & Indikator & Hasil & Skor \\
\hline \multirow[t]{12}{*}{ I. Pembentukan } & \multirow[t]{4}{*}{1.} & Legalisasi & \multirow{4}{*}{$\begin{array}{l}\text { a. KOMIR ditetapkan Gubernur/Bupati } \\
\text { b. Sekretariat Komir ditetapkan Ketua } \\
\text { Harian }\end{array}$} & Tersedia & 4 \\
\hline & & Pembentukan & & & \\
\hline & & KOMIR dan & & Tersedia & 4 \\
\hline & & Sekretariat & & & \\
\hline & \multirow[t]{2}{*}{2.} & \multirow{2}{*}{$\begin{array}{l}\text { Struktur } \\
\text { Organisasi }\end{array}$} & \multirow{2}{*}{$\begin{array}{ll}\text { c. } & \text { KOMIR } \\
\text { d. Sekretariat Komir }\end{array}$} & Tersedia & 3 \\
\hline & & & & Tersedia & 2 \\
\hline & \multirow{6}{*}{\multicolumn{2}{|c|}{ 3. Keanggotaan }} & e. Perwakilan Pemerintahan Daerah & Tersedia & 3 \\
\hline & & & f. Perwakilan P3A/GP3A/IP3A & Tersedia & 3 \\
\hline & & & g. Perwakilan Pengguna Irigasi Lainnya & Tersedia & 2 \\
\hline & & & $\begin{array}{l}\text { h. Perwakilan KOMIR Kabupaten (untuk } \\
\text { KOMIR Provinsi) }\end{array}$ & Tersedia & 0 \\
\hline & & & $\begin{array}{l}\text { i. Proporsi Jumlah Anggota berasal dari } \\
\text { Pemerintah dan Non Pemerintah }\end{array}$ & Tersedia & 3 \\
\hline & & & j. Proporsi Anggota Perempuan & Tersedia & 2 \\
\hline \multirow[t]{7}{*}{ II. Sekretariat } & & Tenaga & k. Staf Pelaksana & Tersedia & 2 \\
\hline & & Pelaksana & 1. Kapasitas Staf Sekretariat & Tersedia & 2 \\
\hline & \multirow{2}{*}{\multicolumn{2}{|c|}{ 5. Program Kerja }} & m. Rencana Kerja & Tersedia & 4 \\
\hline & & & n. Realisasi & Tersedia & 2 \\
\hline & \multirow{2}{*}{\multicolumn{2}{|c|}{$\begin{array}{l}\text { 6. Pelaksanaan } \\
\text { Tugas }\end{array}$}} & o. Fasilitasi/Dukungan Tupoksi KOMIR & Tersedia & 3 \\
\hline & & & $\begin{array}{l}\text { p. Fasilitas Penyediaan Tenaga Ahli/Nara } \\
\text { Sumber/Pakar }\end{array}$ & Tersedia & 0 \\
\hline & 7. & Hasil Kerja & q. Fasilitas Rapat & Tersedia & 3 \\
\hline
\end{tabular}




\begin{tabular}{|c|c|c|c|c|}
\hline Variabel & Parameter & Indikator & Hasil & Skor \\
\hline \multirow{10}{*}{ III. Pendanaan } & Sekretariat & r. Koordinasi & Tersedia & 2 \\
\hline & & s. Notulen Rapat & Tersedia & 4 \\
\hline & & t. Laporan \& Rekomendasi KOMIR & Tersedia & 2 \\
\hline & 8. Fasilitas & u. Ruang Kerja Sekretariat & Tersedia & 4 \\
\hline & Pendukung & v. Kelengkapan Pendukung Lainnya & Tersedia & 4 \\
\hline & $\begin{array}{l}\text { 9. Fasilitas } \\
\text { Pendukung }\end{array}$ & w. Biaya Operasional KOMIR dari APBD & Tersedia & 5 \\
\hline & & $\begin{array}{l}\text { x. Biaya Operasional Sekretariat KOMIR } \\
\text { dari APBD }\end{array}$ & Tersedia & 2 \\
\hline & $\begin{array}{l}\text { 10. Pertangg. } \\
\text { JawabAnggaran }\end{array}$ & y. Laporan Pertanggungjawaban & Tersedia & 5 \\
\hline & & & Total Skor & 70 \\
\hline & & & Kategori & Cukup \\
\hline
\end{tabular}

Sumber : Analisis Data, 2020

Penilaian kinerja komisi irigasi mengunakan 3 variabel yang terdiri dari 1) Pembentukan, 2) Sekretariat dan 3) Pendanaan. Penilaian kinerja pada variabel pembentukan dengan 10 indikator mencapai skor 26 dari nilai maksimal skor variabel pembentukan sebesar 30 atau penilaian kinerja pembentukan telah mencapai 87,67 \%. Pada variabel pembentukan yang menjadi kelemahan adalah pada parameter keanggotaan dengan penjelasan bahwa pengguna jasa irigasi lainnya dan keanggotaan perempuan menjadi kendala utamanya. Penilaian kinerja pada variabel sekretariat dengan 12 indikator mencapai skor 32 dari nilai maksimal skor variabel sekretariat sebesar 40 atau penilaian kinerja sekretariat telah mencapai $80 \%$. Sedang penilaian kinerja pada variabel pendanaan dengan 3 indikator mencapai skor 12 dari nilai maksimal skor variabel pendanaan sebesar 30 atau penilaian kinerja pendanaan telah mencapai $40 \%$. Adapun nilai kinerja kelembagaan komisi irigasi pada 3 (tiga) variabel pembentukan, kesekretariatan dan pendanaan mencapai nilai skor 70 dari nilai maksimal variabel kinerja komisi irigasi sebesar 100 atau penilaian kinerja kinerja komisi irigasi telah mencapai $70 \%$ dengan kategori berkinerja cukup. Dengan hasil penilaian tersebut terdapat kesenjangan kinerja komisi irigasi mencaai $30 \%$ yang menjadi kelemahan ada pengelolaan kelembagaan komisi irigasi dilihat dari 3 variabel yang terdiri dari 1) Pembentukan, 2) Sekretariat dan 3) Pendanaan.

Penilaian kinerja komisi irigasi di atas, memberikan penjelasan pada aspek pembentukan kelembagaan dan kesekretariatan dapat mencapai nilai kinerja yang optimal melebih $80 \%$ tersebut menjelaskan upaya pemeritah daerah memberikan dukungan ada dua variabel telah berjalan dengan baik, sehingga 
kelembagaan komisi irigasi dapat bekerja dan merumuskan kebijakan dengan baik. Hal tersebut dapat terlihat dengan pelaksanaan 3 (tiga) kali sidang komisi irigasi telah menghasilkan beberapa dokumen yang bersifat strategis bagi pengembangan irigasi dan pertanian. Namum ada variabel pendanaan belum dapat mencapai nilai optimal, karena masih $40 \%$ ada dukungan aspek pendanaan. Kondisi tersebut tidak terlepas dari kapasitas fiskal pemerintah daerah dan dukungan terhadap pelaksanaan program (Eko Aristanto \& Christina Sri Ratnaningsih, 2019). Secara keseluruhan dalam pengelolaan kelembagaan komisi irigasi masih terdapat beberapa kendala yang perlu untuk di tingkatkan meliputi ketersediaan tenaga ahli dan narasumber dalam berbagai pelaksanaan kegiatan komisi irigasi, masih rendahnya dukungan pendanaan untuk kegiatan operasional komisi irigasi, dan sekretariat komisi irigasi yang masih bersifat sementara (sewa). Berbagai kendala tersebut nampaknya akan mampu diselesaikan oleh pemerintah daerah menekankan prioritas dan penguatan alokasi anggaran yang berkaitan dengan bidang irigasi dan pertanian. Hal tersebut menjadi penting menginggat bidang irigasi dan pertanian berkonstribusi bagi perekonomian masyarakat, kesejahteraan petani dan penyediaan lapangan pekerjaan bagi masyarakat pedesaan. Pengembagan kelembagaan komisi irigasi juga menjadi bagian penting bagi pencapaian kinerja Program Integrated Participatory Development and Managemet of Irrigation Program (IPDMIP) di Kabupaten Pandeglang.

\section{KESIMPULAN DAN SARAN}

Penilaian kinerja Komisi Irigasi Kabupaten Pandeglang menjadi bagian pemantauan terhadap kelembagaan dengan pendanaan dari pemerintah daerah yang mendukung perumusan kebijakan bidang irigasi dan pertanian bagi pemerintah daerah. Untuk pencapaian kinerja komisi irigasi telah melaksanakan i) Pengesahan Tata Tertib Sidang Komisi Irigasi, ii) Penetapan RTTG dan RTTD masa Tanam 2019 - 2020 melalui SK. Bupati Pandeglang, iii) Rencana Kerja Tahunan dan 5 Tahunan Komisi Irigasi, iv) Pembahasan Peraturan Daerah Irigasi pasca pemberlakukan Undang-Undang Nomor 17 Tahun 2019 tentang Sumber Daya Air, v) Penyediaan Tenaga Ahli yang membantu peningkatan kinerja komisi irigasi. Adapun kinerja kelembagaan komisi irigasi pada 3 (tiga) variabel pembentukan, kesekretariatan dan pendanaan mencapai nilai skor 61 dari nilai maksimal variabel 
kinerja komisi irigasi sebesar 100 atau penilaian kinerja komisi irigasi telah mencapai $70 \%$ dengan kategori kinerja cukup. Secara keseluruhan dalam pengelolaan kelembagaan komisi irigasi masih terdapat beberapa kendala yang perlu untuk di tingkatkan meliputi ketersediaan tenaga ahli dan narasumber dalam berbagai pelaksanaan kegiatan komisi irigasi, masih rendahnya dukungan pendanaan untuk kegiatan operasional komisi irigasi, dan sekretariat komisi irigasi yang masih bersifat sementara (sewa). Rekomendasi dalam rangka peningkatan kinerja Komisi Irigasi Kabupaten Pandeglang antara lain;

1) Komisi Irigasi membutuhkan payung hukum yang lebih tinggi dan kuat berupa Peraturan Bupati maupun Peraturan Daerah, sehingga di harapkan adanya peraturan yang kuat tersebut dapat memaksimalkan berjalannya program kerja dan kegiatan Komisi Irigasi di Kabupaten Pandeglang; ii) perlu peningkatan kapasitas pada pengelolaan komisi irigasi dengan diadakan melaksanakan bimbingan teknik, pelatihan dan studi banding.

\section{DAFTAR PUSTAKA}

Badan Perencanaan Pembangunan Daerah Kabupaten Pandeglang. (2019a). Keputusan Bupati Pandeglang Nomor 050/Kep.221-Huk/2019 tentang Pembentukan Komisi Irigasi Kabuaten Pandeglang. Badan
Perencanaan Pembangunan Daerah Kabupaten Pandeglang.

Badan Perencanaan Pembangunan Daerah Kabupaten Pandeglang. (2019b). Laporan Komisi Irigasi Kabupaten Pandegelag Tahun 2019. Badan Perencanaan Pembangunan Daerah Kabupaten Pandeglang.

BPS Kabupaten Pandeglang. (2019). Statistik Daerah Kabupaten Pandeglang 2019. BPS Kabupaten Pandeglang.

Djito. (2016). Merancang Kelembagaan Pengelolaan Irigasi Kedepan. Buletin Infrastruktur Daerah, Tahun 1, Edisi 03, 10-15.

Eko Aristanto. (2020a). Capaian Konsultan Pendukung Dalam Pelaksanaan Program Integrated Participatory Development \& Management of Irrigation Program (IPDMIP) di Kabupaten Pandeglang dan Kabupaten Serang. Buletin Pembangunan Daerah, Vol. 1, No. 1, $1-5$.

Eko Aristanto. (2020b). Pemetaan Aspek Sosial, Ekonomi dan Kelembagaan Sebagai Daya Dukung Pelaksanaan Rehabilitasi Daerah Irigasi (DI) Ciliman Provinsi Banten. LPPM Universitas Merdeka Malang.

Eko Aristanto. (2020c). Profil dan Kinerja Kelembagaan Perkumpulan Petani Pemakai Air (P3A) Daerah Irigasi (DI) Ciliman di Kabupaten Lebak dan Kabupaten Pandeglang. LPPM Universitas Merdeka Malang.

Eko Aristanto, \& Christina Sri Ratnaningsih. (2019). Analisis Kemampuan dan Kemandirian Keuangan Daerah Calon Penerima Pinjaman dan Hibah Luar Negeri Program Air Bersih dan Sanitasi pada Kegiatan Green Book 2018 dan Indikasi Kegiatan Blue Book 2019. LPPM Universitas Merdeka Malang.

Kementerian Dalam Negeri. (2018). Panduan Pemantauan dan Penilaian 
Kinerja Komisi Irigasi (KOMIR) IPDMIP. Kementerian Dalam Negeri. Kementerian Pekerjaan Umum dan Perumahan Rakyat. (2017). Pedoman Pelaksanaan Program Integrated Participatory Development and Management of Irrigation Program (IPDMIP). Kementerian Pekerjaan Umum dan Perumahan Rakyat.

Kurniasih Budi. (2018, Mei). Pengelolaan Irigasi dan Drainase Dukung Ketahanan Pangan. Kompas.Com. https://ekonomi.kompas.com/read/20 18/05/12/122105126/pengelolaanirigasi-dan-drainase-dukungketahanan-pangan?page $=$ all

Sekretariat Negara Republik Indonesia. (2006). Peraturan Pemerintah Republik Indonesia Nomor 20 Tahun 2006 tentang Irigasi. Sekretariat Negara Republik Indonesia.

Tri Bastuti Purwantini, \& Rita Nur Suhaeti. (2017). Irigasi Kecil: Kinerja, Masalah dan Solusinya. Forum Penelitian Agro Ekonomi, 35 No. 2, 91-105. 